\title{
Association of IL10-1082 and IFN- $\gamma+874$ Polymorphisms with Cervical Cancer among Tunisian Women
}

\author{
Sabrina Zidi, ${ }^{1}$ Yosra Benothmen, ${ }^{1}$ Ikram Sghaier, ${ }^{1}$ Ezzeddine Ghazoueni, ${ }^{2}$ Amel Mezlini, ${ }^{3}$ \\ Bouraoui Slimen, ${ }^{2}$ and Besma Yacoubi-Loueslati ${ }^{1}$ \\ ${ }^{1}$ Laboratory of Micro-Organisms and Active Biomolecules, Faculty of Sciences of Tunis, El Manar University, \\ 2092 El Manar I, 1092 Tunis, Tunisia \\ ${ }^{2}$ Laboratory of Immunology, Military Hospital of Tunis, 1008 Tunis, Tunisia \\ ${ }^{3}$ Salah Azeiz Oncology Institute, 1006 Tunis, Tunisia
}

Correspondence should be addressed to Sabrina Zidi; zidisabrina86@gmail.com

Received 21 November 2013; Accepted 18 December 2013; Published 6 February 2014

Academic Editors: S. Boisson-Dupuis and P. A. Slominsky

Copyright (C) 2014 Sabrina Zidi et al. This is an open access article distributed under the Creative Commons Attribution License, which permits unrestricted use, distribution, and reproduction in any medium, provided the original work is properly cited.

\begin{abstract}
Objective. The aim of this study was to investigate the role of IL10-1082 and IFN- $\gamma+874$ polymorphisms in susceptibility to cervical cancer among Tunisian women. Study Design. The IL10-1082 and IFN- $\gamma+874$ polymorphisms were analyzed by ARMS-PCR in 160 healthy women and 122 with cervical cancer. The search for associations between those polymorphisms and cervical cancer was based on the $\chi^{2}$ test or Fisher's exact test. Results. The IFN- $\gamma+874$ polymorphism showed significant increased frequency of T allele in healthy controls compared with patients $(\mathrm{OR}=0.71,95 \% \mathrm{CI}=0.50-1.01$, and $P=0.0459)$ and individuals with homozygote IFN$\gamma+874 \mathrm{~T} / \mathrm{T}$ genotype were at lesser risk of cervical cancer $(\mathrm{OR}=0.53,95 \% \mathrm{CI}=0.31-0.92$, and $P=0.015)$. However, carriers of allele have higher risk for developing cervical cancer $(\mathrm{OR}=1.88,95 \% \mathrm{CI}=1.09-3.24$, and $P=0.015)$. At the polymorphic nucleotide in position 1082 of the IL10 promoter, no differences were found between patients and controls subjects. Conclusion. Our study shows that the T/T genotype polymorphism of IFN $-\gamma+874 \mathrm{~T}>\mathrm{A}$ is a protective factor for cervical cancer among Tunisian women.
\end{abstract}

\section{Introduction}

Worldwide, cervical cancer (CC) is the second most common malignancy in women, with approximately $80 \%$ of cases arising in developing countries [1]. The major risk factor for this tumour is infection with specific high-risk types of human papillomavirus (HPV) [2]. However, only a minority of women who have persistent infection with high-risk types of HPV develop CC. Therefore, other factors including genetics factors appear to play a role in the susceptibility and the development of cervical malignancy $[3,4]$.

Several studies have identified polymorphisms in cytokine gene regulatory regions that correlated with intraindividual variations in cytokine production $[5,6]$. In addition, cytokine gene polymorphisms have been implicated in various human diseases [7], such as Epstein-Barr virus associated gastric carcinoma [8], Alzheimer's [9], and rheumatoid arthritis [10], and in patients presenting with severe sepsis after trauma [11], ovarian cancer [12] and the risk of CC [13$18]$.

One of the polymorphisms that are associated with low, medium, or high production of IL10 corresponds to an A to $\mathrm{G}$ transition which is situated in the promoter region of the gene at position 1082 (rs1800896) [19]. The T to A change in the +874 (rs2430561) position from the translation start site in the first intron of IFN- $\gamma$ gene increases in vitro transcription of IFN- $\gamma$ and may affect disease susceptibility [20]. The aim of the present study was to evaluate the impact of IL10-1082 G $>$ A and IFN $-\gamma+874$ T $>$ A polymorphisms on susceptibility to $\mathrm{CC}$ among Tunisian women.

\section{Materials and Methods}

2.1. Subjects: Cases and Controls. In a retrospective study from October 2010 to April 2012, 122 Tunisian cases with invasive CC confirmed by cervical biopsy were consecutively 
TABLE 1: Primer sequences used in polymerase chain reactions with specific sequence primers for the detection of cytokine gene polymorphisms.

\begin{tabular}{lcr}
\hline Cytokine polymorphisms & & Gene sequence $^{\prime}$ \\
\hline \multirow{2}{*}{ Interferon-gamma (intron1 +874) } & Common primer & $5^{\prime}$-TCA ACA AAG CTG ATA CTC CA-3' \\
& T allele primer & $5^{\prime}$-TTC TTA CAA CAC AAA ATC AAA TCT-3' \\
& A allele primer & $5^{\prime}$-TTC TTA CAA CAC AAA ATC AAA TCA-3' \\
\hline \multirow{2}{*}{ Interleukin-10 (promoter -1082) } & Common primer & $5^{\prime}$-CAG TGC CAA CTG AGA ATT TGG-3' \\
& G allele primer & $5^{\prime}$-CTA CTA AGG CTT CTT TGG GAG-3' \\
Internal control & A allele primer & $5^{\prime}$-CTA CTA AGG CTT CTT TGG GAA-3' \\
& Primerl & $5^{\prime}$-GCC TTC CCA ACC ATT CCC TTA-3' \\
& Primer2 & $5^{\prime}$-TCA CGG ATT TCT GTT GTG TTT C-3' \\
\hline
\end{tabular}

recruited from the Salah Azeiz Oncology Institute (SAI, Tunisia). Cancer diagnosis was established by clinical examination and biopsy, confirmed by two senior pathologists of the SAI. Clinical data were obtained by questionnaire, personal interviews, and review of case records.

Tumours were staged according to the FIGO classification (International Federation of Gynecology and Obstetrics, http://www.figo.org/) [21]. Controls (160) were cancer-free women unrelated and matched for age and ethnicity. They also present negative cervical cytology and were recruited from three medical centres: Tunisian Military Hospital, Regional Hospital of Nefta, and Disponsor of Ettadhamen City. Informed consent was obtained from all participants, and the study was approved by the local ethical committee of SAI.

2.2. Blood Collection. Five milliliters of venous blood with EDTA, as an anticoagulant, was collected from each woman. For patients, the blood was obtained prior to radiation therapy or chemotherapy. Genomic DNA was extracted using QIAamp DNA blood Mini Kit (Qiagen GmbH, Hilden).

2.3. Genotyping. The polymorphisms IFN- $\gamma+874 \quad \mathrm{~T}>\mathrm{A}$ (rs2430561) and IL10-1082 G>A (rs1800896) were genotyped in subjects using amplification refractory mutation system polymerase chain reaction method (ARMS-PCR) [22].

This reaction was performed in a total volume of $15 \mu \mathrm{L} ; 0.25 \mathrm{mM}$ each deoxynucleotide triphosphates, 1X PCR buffer containing $10 \mathrm{mM}$ Tris- $\mathrm{HCl}, \mathrm{pH} 8.6,50 \mathrm{mM} \mathrm{KCl}$, $1.5 \mathrm{mM} \mathrm{MgCl}_{2}, 0.1 \mu \mathrm{L}$ of genomic DNA, 0.1 units of Taq polymerase, $0.25 \mu \mathrm{L}$ of generic primer and $0.25 \mu \mathrm{L}$ of specific primer, $0.25 \mu \mathrm{L}$ of control primers by which a 426 base pair human growth hormone sequence was amplified were used to confirm successful PCR amplification.

The sequences of those primers are listed in Table 1 [23]. The final volume was adjusted up to $15 \mu \mathrm{L}$ with sterile water. The reaction conditions were as follows: $95^{\circ} \mathrm{C}$ for $1 \mathrm{~min} ; 10$ cycles at $95^{\circ} \mathrm{C}$ for $15 \mathrm{~s}, 60^{\circ} \mathrm{C}$ for $50 \mathrm{~s}$, and $72^{\circ} \mathrm{C}$ for $40 \mathrm{~s}$; and 25 cycles at $95^{\circ} \mathrm{C}$ for $20 \mathrm{~s}, 56^{\circ} \mathrm{C}$ for $50 \mathrm{~s}$, and $72^{\circ} \mathrm{C}$ for $50 \mathrm{~s}$, with a final extension of $5 \mathrm{~min}$ at $72^{\circ} \mathrm{C}$ in the last cycle. The PCR products were separated by electrophoresis on a $2 \%$ agarose gel stained with ethidium bromide $(0.5 \mathrm{mg} / \mathrm{mL})$ and visualized with ultraviolet light.

2.4. Statistical Analysis. Allele and genotype frequencies of IFN- $\gamma+874 \mathrm{~T}>\mathrm{A}$ and IL10-1082 G>A polymorphisms were calculated by direct counting. The distribution of these two polymorphisms in patients with cervical cancer and healthy controls was compared using $\chi^{2}$ test or the Fisher exact test. A $P$ value $<0.05$ was considered to be statistically significant. The strength of the association of individual alleles or genotypes with risk of invasive CC was measured by calculating the odds ratios (OR) and 95\% confidence intervals (95\% CI) using the Epi info 6 package program (http://wwwn.cdc.gov/epiinfo/html/downloads.htm).

\section{Results}

The median age of the 122 patients with CC was 52 years, with a range of 30-81 years. Diagnoses of squamous cell carcinoma were confirmed by histopathological examination as the International Federation of Gynecology and Obstetrics; the distribution of the sample according to the FIGO stage is as follows: stage I (21.31\%), stage II (38.52\%), stage III (25.41\%), and stage IV (6.56\%).

The median age of the 160 healthy controls was 52 years, with a range of 30-80 years. According the menopausal status of women, our sample is divided into two groups; 30 (24.59\%) patients and $75(46.88 \%)$ healthy controls are premenopausal, and $92(75.41 \%)$ patients and $85(53.12 \%)$ healthy controls are postmenopausal (Table 2).

Tables 3 and 4 present the allele and genotype distribution of IFN- $\gamma+874$ and IL-10-1082 polymorphisms within patients with CC and healthy controls, respectively.

The allelic frequencies of IFN $-\gamma+874$ polymorphism were altered among patients and controls. T and A allele frequency were, respectively, $61 \%$ and $39 \%$ in controls, $54 \%$ and $46 \%$ of patients. With regard to the allele, the frequency distributions differ significantly from those of the controls and patients. We showed a higher prevalence of the $\mathrm{T}$ allele in healthy women compared with patients with $\mathrm{CC}(\mathrm{OR}=0.71,95 \% \mathrm{CI}=0.50-$ 1.01 , and $P=0.0459$ ) (Table 3). 
TABLE 2: Demographic and tumour characteristics of the studied population.

\begin{tabular}{lcc}
\hline & Patients $n(\%)$ & Controls $n(\%)$ \\
\hline $\begin{array}{l}\text { All women } \\
\text { Age on diagnostic (year) }\end{array}$ & 122 & 160 \\
$30-40$ & $9(7.38)$ & $65(40.62)$ \\
$41-50$ & $33(27.05)$ & $60(37.5)$ \\
$51-60$ & $34(27.86)$ & $24(15)$ \\
$61-70$ & $24(19.67)$ & $10(6.25)$ \\
$71-80$ & $21(17.24)$ & $1(0.63)$ \\
81 & $1(0.80)$ & $0(0)$ \\
Status of menopause & & $75(46.88)$ \\
Premenopausal & $30(24.59)$ & $85(53.12)$ \\
Postmenopausal & $92(75.41)$ & \\
Tumour stage (FIGO) & & \\
Stage I & $26(21.31)$ & \\
Stage II & $47(38.52)$ & \\
Stage III & $31(25.41)$ & \\
Stage IV & $8(6.56)$ & \\
ND & $10(8.2)$ & \\
\hline
\end{tabular}

ND: not determined; FIGO: International Federation of Gynecology and Obstetrics.

The frequency of IFN- $\gamma+874$ T/T genotype was significantly higher in controls (40\%) compared with cases with CC (26.23\%). Women with homozygote IFN $-\gamma+874 \mathrm{~T} / \mathrm{T}$ genotype were at lesser risk of cervical cancer $(\mathrm{OR}=0.53$, $95 \% \mathrm{CI}=0.31-0.92$, and $P=0.015)$. Carriers of allele A have an increased risk for developing $\mathrm{CC}(\mathrm{OR}=1.88,95 \% \mathrm{CI}=$ $1.09-3.24$, and $P=0.015$ ).

Taking into account that the $\mathrm{T}$ allele is much more frequent than the A allele in healthy controls, therefore, it is a protective factor for CC.

At the polymorphic nucleotide 1082 of the IL10 promoter, the $\mathrm{G}$ and $\mathrm{A}$ allele frequencies of the control group were $55 \%$ and $45 \%$ and those of patients were $49 \%$ and $51 \%$, respectively.

No significant difference was found in allelic frequencies of IL10-1082 G>A polymorphism between patients with cervical cancer and healthy controls (Table 3 ).

At genotype level, IL-10-1082 polymorphism showed a higher prevalence of women carrying a homozygous AA genotype in cases (18\%) than in controls (11.25\%). However, this result did not reach statistical significance $(P=0.105)$.

In addition, when grouping the population considering individuals as being carriers or not carriers of a specific allele, no differences were found between patients and control subjects $(P>0.05)$ (Table 4$)$.

\section{Discussion}

It is well established that individual genetic variations may affect the host's response to malignant tumours [24]. As cytokine gene polymorphisms play a role in the immune response, several studies have investigated the association between cytokine gene polymorphisms and cancers. However, the results vary between population groups [25-27].
Given the role of TNF- $\gamma$ and IL10 in the immune response to tumor cells and cancer pathogenesis, this study evaluated the effect of two polymorphisms IFN- $\gamma+874$ and IL10-1082 on susceptibility to CC among Tunisian women.

IFN- $\gamma$ is a Thl proinflammatory cytokine which plays a pivotal role in the induction of immune-mediated inflammatory responses and the defence against viruses and intracellular pathogens [28]. Defective IFN- $\gamma$ production may be associated with increased disease severity in cancer patients [29]. The IFN- $\gamma+874$ polymorphism, located in the first intron of human IFN- $\gamma$ gene, is a single nucleotide polymorphism (SNP) +874 changing a thymine (T) to an adenine (A). The specific sequence of the $+874 \mathrm{~T}$ allele provides a binding site for the transcription factor nuclear factor $\mathrm{kB}$ (NFkB) correlates with high IFN- $\gamma$ expression, whereas the A allele correlates with low expression [20,30,31].

IFN- $\gamma+874 \mathrm{~T}>\mathrm{A}$ gene polymorphism has been shown to be associated with chronic immune diseases $[32,33]$. In fact, it is possible that low IFN- $\gamma$ production may impair the antiviral response against tumour progression, rendering these individuals more susceptible to this viral infection. The present study found that carriers of allele A (being to genotypes $\mathrm{A} / \mathrm{A}$ and $\mathrm{A} / \mathrm{T}$ ) present an increased risk for developing CC, and the IFN $-\gamma+874 \mathrm{~T} / \mathrm{T}$ genotype may protect against the development of CC. In agreement with our results, a recent study carried out by Wang et al. in a Chinese population revealed that the IFN $-\gamma+874 \mathrm{~A} / \mathrm{A}$ genotype may increase the risk for developing CC while the IFN $-\gamma+874 \mathrm{~T} / \mathrm{T}$ genotype is a protective factor for this tumoral pathology [18]. Two studies carried out successively by Tamandani et al. and Gangwar et al. in two populations of Indian women reported, respectively, that genotypes $\mathrm{A} / \mathrm{T}$ and $\mathrm{A} / \mathrm{A}+\mathrm{A} / \mathrm{T}$ increase the risk of $\mathrm{CC}$ and that the AA genotype was more common in cases with CIN than controls $[34,35]$. In concordance with these results the A/A genotype was associated with increased susceptibility to CC in Swedish women [36]. However, Govan et al. found no association between the IFN $-\gamma+874$ alleles and/or genotypes susceptibility to CC in South African women [37]. No association was found between the IFN- $\gamma+874$ TA genotype and susceptibility to HPV-related cervical lesions in Brazilian women [38]. In order to prove a more precise estimation of IFN- $\gamma+874 \mathrm{~T}>\mathrm{A}$ polymorphism in CC, two meta-analyses were recently performed. The first including 17 case-control studies, from which four were carried out on CC, showed a significant increased risk of this tumour for heterozygous A/T cases [39]. The second was based on 32 case-control studies on different cancer types. Of these studies, seven include CC type. This meta-analysis did not show any association between IFN $-\gamma+874 \mathrm{~A}>\mathrm{T}$ polymorphism and different cancer types [25].

All these studies are pertinent; however, they offer conflicting results which could be explained by differences in linkage disequilibrium and population structure. Therefore, further well-designed larger studies are warranted in order to better evaluate the association between IFN $-\gamma+874 \mathrm{~T}>\mathrm{A}$ polymorphism and CC.

IL10 is a multifunctional cytokine implicated in inflammation, immunity, and cellular organization. It was also proposed to play an important role in cancer biology [40]. 
TABLE 3: Allele frequencies of IFN- $\gamma+874$ and IL-10 polymorphisms in cases and controls and risk analysis for cervical cancer.

\begin{tabular}{lcccc}
\hline SNPs & Allele & $\begin{array}{c}\text { Controls } \\
n(\%)\end{array}$ & $\begin{array}{c}\text { Cases } \\
n(\%)\end{array}$ & OR (95\% CI $)$ \\
\hline IFN- $\gamma+874$ T $>$ A & T & $196(61)$ & $129(54)$ & $0.71(\mathrm{CI}=0.50-1.01)$ \\
\hline IL-10-1082 G>A & A & $124(39)$ & $115(46)$ & 0.0459 \\
& G & $176(55)$ & $119(49)$ & $0.78(\mathrm{CI}=0.55-1.1)$ \\
\hline
\end{tabular}

SNP: single nucleotide polymorphism; OR: odds ratio; nominal value of comparison; $P>0.05$ : no significant association; degree of freedom $=1$. Value in bold is statistically significant at the $5 \%$ level.

TABLE 4: Frequency distribution of the IFN- $\gamma+874$, IL-10-1082 genotypes among cases and controls and risk analysis for cervical cancer.

\begin{tabular}{|c|c|c|c|c|c|}
\hline SNP & Genotype & $\begin{array}{c}\text { Controls } \\
n(\%)\end{array}$ & $\begin{array}{l}\text { Cases } \\
n(\%)\end{array}$ & OR (95\% CI) & $P$ value \\
\hline \multirow{4}{*}{ IFN- $\gamma+874$ T $>$ A } & $\mathrm{T} / \mathrm{T}$ & $64(40)$ & $32(26.23)$ & $0.53(\mathrm{CI}=0.31-0.92)$ & 0.015 \\
\hline & $\mathrm{T} / \mathrm{A}$ & $68(42.5)$ & $65(53.27)$ & $1.54(\mathrm{CI}=0.93-2.55)$ & 0.072 \\
\hline & $\mathrm{A} / \mathrm{A}$ & $28(17.5)$ & $25(20.5)$ & $1.22(\mathrm{CI}=0.64-2.31)$ & 0.524 \\
\hline & Carrier A & $96(60)$ & $90(73.77)$ & $1.88(\mathrm{CI}=1.09-3.24)$ & 0.015 \\
\hline \multirow{4}{*}{ IL-10-1082 G>A } & $\mathrm{G} / \mathrm{G}$ & $34(21.25)$ & $19(15.6)$ & $0.68(\mathrm{CI}=0.35-1.32)$ & 0.226 \\
\hline & $\mathrm{G} / \mathrm{A}$ & $108(76.5)$ & $81(66.4)$ & $0.95(\mathrm{CI}=0.56-1.62)$ & 0.844 \\
\hline & $\mathrm{A} / \mathrm{A}$ & $18(11.25)$ & $22(18)$ & $1.74(\mathrm{CI}=0.84-3.59)$ & 0.105 \\
\hline & Carrier A & $126(87.75)$ & $103(84.4)$ & $1.46(\mathrm{CI}=0.76-2.85)$ & 0.226 \\
\hline
\end{tabular}

SNP: single nucleotide polymorphism; OR: odds ratio; nominal value of comparison; $P>0.05$ : no significant association; degree of freedom $=1$. Values in bold are statistically significant at the $5 \%$ level.

It has been reported that several polymorphic sites in the IL10 gene may influence the transcription and expression level of IL10 and consequently play a role in susceptibility to cancer [41].

Indeed, the effect of IL10-1082 G>A polymorphism and the risk of CC which has been investigated in a several variety of case-control studies. Nevertheless, the obtained results are controversial. In fact, this polymorphism has been found to be associated with an increased risk of CC in populations from Zimbabwe and Japan [42], while studies in South Africa [37], Netherlands [43], Hungary [44], Argentine [45], and Tunisia (present study) did not find any association. A meta-analysis was recently performed on eight studies for IL-10-1082 G>A polymorphism in CC and showed no effect on cervical cancer risk in the overall analysis [26]. So, the implication of the IL10-1082 G>A polymorphism in the susceptibility to CC is still ambiguous.

In conclusion, this study evaluated two cytokine gene polymorphisms IFN- $\gamma+874$ and IL10-1082 that may modulate the susceptibility to cervical cancer among Tunisian women. The data suggest that there is no association between the risk of CC and IL10-1082 polymorphism. However, carriers of IFN- $\gamma+874$ T/A and A/A genotypes present an increased risk for the development of CC, while the homozygous IFN$\gamma+874 \mathrm{~T} / \mathrm{T}$ cases have a decreased risk for this malignancy. These results need to be verified by further studies involving larger numbers of patients and healthy controls. Furthermore, larger investigations are needed in order to better evaluate the involvement of these polymorphisms in the oncogenesis of CC.

\section{Conflict of Interests}

The authors declare that there is no conflict of interests regarding the publication of this paper.

\section{References}

[1] A. Jemal, F. Bray, M. M. Center, J. Ferlay, E. Ward, and D. Forman, "Global cancer statistics," CA: Cancer Journal for Clinicians, vol. 61, no. 2, pp. 69-90, 2011.

[2] F. X. Bosch, A. Lorincz, N. Muñoz, C. J. L. M. Meijer, and K. V. Shah, "The causal relation between human papillomavirus and cervical cancer," Journal of Clinical Pathology, vol. 55, no. 4, pp. 244-265, 2002.

[3] J. Cuzicka, M. Arbynb, R. Sankaranarayananc, V. Tsud, and G. Roncoe, "Overview of human papillomavirus-based and other novel options for cervical cancer screening in developed and developing countries," Vaccine, vol. 26S, supplement 10, pp. K29-K41, 2008.

[4] A. Hildesheim and S. S. Wang, "Host and viral genetics and risk of cervical cancer: a review," Virus Research, vol. 89, no. 2, pp. 229-240, 2002.

[5] A. Pawlik, M. Baskiewicz-Masiuk, B. Machalinski, and B. Gawronska-Szklarz, "Association of cytokine gene polymorphisms and the release of cytokines from peripheral blood mononuclear cells treated with methotrexate and dexamethasone," International Immunopharmacology, vol. 6, no. 3, pp. 351$357,2006$.

[6] M. C. Warlé, A. Furbun, H. J. Metseluur, W. C. J. Hop, C. Perrty, and P. E. Zondervun, "Are cytokine gene polymorphisms related to in vitro cytokine production profiles?" Liver Transplantation, vol. 9, no. 2, pp. 170-181, 2003. 
[7] J. Bidwell, L. Keen, G. Gallagher et al., "Cytokine gene polymorphism in human disease: on-line databases, Supplement 1," Genes and Immunity, vol. 2, no. 2, pp. 61-70, 2001.

[8] M.-S. Wu, S.-P. Huang, Y.-T. Chang et al., "Tumor necrosis factor- $\alpha$ and interleukin-10 promoter polymorphisms in Epstein-Barr virus-associated gastric carcinoma," Journal of Infectious Diseases, vol. 185, no. 1, pp. 106-109, 2002.

[9] N. Shibata, T. Ohnuma, T. Takahashi et al., "Effect of IL6 polymorphism on risk of Alzheimer disease: genotypephenotype association study in Japanese cases," American Journal of Medical Genetics, vol. 114, no. 4, pp. 436-439, 2002.

[10] B. Mugnier, N. Balandraud, A. Darque, C. Roudier, J. Roudier, and D. Reviron, "Polymorphism at position -308 of the tumor necrosis factor $\alpha$ gene influences outcome of infliximab therapy in rheumatoid arthritis," Arthritis and Rheumatism, vol. 48, no. 7, pp. 1849-1852, 2003.

[11] G. E. O'Keefe, D. L. Hybki, and R. S. Munford, "The G $\rightarrow$ A single nucleotide polymorphism at the -308 position in the tumor necrosis factor- $\alpha$ promoter increases the risk for severe sepsis after trauma," Journal of Trauma, vol. 52, no. 5, pp. 817825, 2002.

[12] A. W. Bushley, R. Ferrell, K. McDuffie et al., "Polymorphisms of interleukin (IL)- $1 \alpha$, IL-1 $\beta$, IL-6, IL-10, and IL-18 and the risk of ovarian cancer," Gynecologic Oncology, vol. 95, no. 3, pp. 672679, 2004.

[13] I. Duarte, A. Santos, H. Sousa et al., "G-308A TNF- $\alpha$ polymorphism is associated with an increased risk of invasive cervical cancer," Biochemical and Biophysical Research Communications, vol. 334, no. 2, pp. 588-592, 2005.

[14] X. Chen, S. Han, S. Wang et al., "Interactions of IL-12A and IL12B polymorphisms on the risk of cervical cancer in Chinese women," Clinical Cancer Research, vol. 15, no. 1, pp. 400-405, 2009.

[15] H. Sousa, A. M. Santos, R. Catarino, D. Pinto, J. Moutinho, and P. Canedo, "IL-1RN VNTR polymorphism and genetic susceptibility to cervical cancer in Portugal," Molecular Biology Reports, vol. 39, no. 12, pp. 10837-10842, 2012.

[16] J. W. Kim, J. W. Roh, N. H. Park, Y. S. Song, S. B. Kang, and H. P. Lee, "Interferon, alpha 17 (IFNA17) Ile184Arg polymorphism and cervical cancer risk," Cancer Letters, vol. 189, no. 2, pp. 183188, 2003.

[17] E. S. Calhoun, R. M. McGovern, C. A. Janney et al., "Host genetic polymorphism analysis in cervical cancer," Clinical Chemistry, vol. 48, no. 8, pp. 1218-1224, 2002.

[18] Q. Wang, C. Zhang, S. Walayat, H. W. Chen, and Y. Wang, "Association between cytokine gene polymorphisms and cervical cancer in a Chinese population," European Journal of Obstetrics Gynecology and Reproductive Biology, vol. 158, no. 2, pp. 330333, 2011.

[19] L. Miteva and S. Stanilova, “The combined effect of interleukin (IL)-10 and IL-12 polymorphisms on induced cytokine production," Human Immunology, vol. 69, no. 9, pp. 562-566, 2008.

[20] V. Pravica, C. Perrey, A. Stevens, J.-H. Lee, and I. V. Hutchinson, "A single nucleotide polymorphism in the first intron of the human IFN- $\gamma$ gene: absolute correlation with a polymorphic CA microsatellite marker of high IFN- $\gamma$ production," Human Immunology, vol. 61, no. 9, pp. 863-866, 2000.

[21] J. H. Shepherd, "Staging announcement: FIGO staging of gynecologic cancers; cervical and vulva," International Journal of Gynecological Cancer, vol. 5, pp. 319-323, 1995.

[22] C. Perrey, S. J. Turner, V. Pravica, W. M. Howell, and I. V. Hutchinson, "ARMS-PCR methodologies to determine IL-10,
TNF- $\alpha$, TNF- $\beta$ and TGF- $\beta 1$ gene polymorphisms," Transplant Immunology, vol. 7, no. 2, pp. 127-128, 1999.

[23] C. Perrey, V. Pravica, P. J. Sinnott, and I. V. Hutchinson, "Genotyping for polymorphisms in interferon- $\gamma$, interleukin10 , transforming growth factor- $\beta 1$ and tumour necrosis factor- $\alpha$ genes: a technical report," Transplant Immunology, vol. 6, no. 3, pp. 193-197, 1998.

[24] T. L. Whiteside, "Immune suppression in cancer: effects on immune cells, mechanisms and future therapeutic intervention," Seminars in Cancer Biology, vol. 16, no. 1, pp. 3-15, 2006.

[25] F. Liu, B. Li, Y.-G. Wei et al., "IFN- $\gamma+874$ A/T polymorphism and cancer risk: an updated analysis based on 32 case-control studies," Cytokine, vol. 56, no. 2, pp. 200-207, 2011.

[26] J. Ni, Y. Ye, F. Teng, and Q. Wu, "Interleukin 10 polymorphisms and cervical cancer risk: a meta-analysis," International Journal of Gynecological Cancer, vol. 23, no. 1, pp. 126-133, 2012.

[27] Y.-G. Wei, F. Liu, B. Li et al., "Interleukin-10 gene polymorphisms and hepatocellular carcinoma susceptibility: a metaanalysis," World Journal of Gastroenterology, vol. 17, no. 34, pp. 3941-3947, 2011.

[28] K. Schroder, P. J. Hertzog, T. Ravasi, and D. A. Hume, "Interferon- $\gamma$ : an overview of signals, mechanisms and functions," Journal of Leukocyte Biology, vol. 75, no. 2, pp. 163-189, 2004.

[29] A. Gey, P. Kumari, A. Sambandam et al., "Identification and characterisation of a group of cervical carcinoma patients with profound downregulation of intratumoral type 1 (IFN $\gamma)$ and Type 2 (IL-4) cytokine mRNA expression," European Journal of Cancer, vol. 39, no. 5, pp. 595-603, 2003.

[30] J. H. Bream, M. Carrington, S. O’Toole et al., "Polymorphisms of the human IFNG gene noncoding regions," Immunogenetics, vol. 51, no. 1, pp. 50-58, 2000.

[31] F. P. Schena, G. Cerullo, D. D. Torres et al., "Role of interferon$\gamma$ gene polymorphisms in susceptibility to IgA nephropathy: a family-based association study," European Journal of Human Genetics, vol. 14, no. 4, pp. 488-496, 2006.

[32] T. Satoh, J. P. Pandey, Y. Okazaki et al., "Single nucleotide polymorphisms of the inflammatory cytokine genes in adults with chronic immune thrombocytopenic purpura," British Journal of Haematology, vol. 124, no. 6, pp. 796-801, 2004.

[33] Z. Ben-Ari, E. Mor, O. Papo et al., "Cytokine gene polymorphisms in patients infected with hepatitis B virus," American Journal of Gastroenterology, vol. 98, no. 1, pp. 144-150, 2003.

[34] M. K. K. Tamandani, R. C. Sobti, M. Shekari, M. Mukesh, and V. Suri, "Expression and polimorphism of IFN- $\gamma$ gene in patients with cervical cancer," Experimental Oncology, vol. 30, no. 3, pp. 224-229, 2008.

[35] R. Gangwar, S. Pandey, and R. D. Mittal, "Association of interferon- $\alpha+874 \mathrm{~A}$ polymorphism with the risk of developing cervical cancer in north-Indian population," BJOG, vol. 116, no. 12, pp. 1671-1677, 2009.

[36] E. L. Ivansson, I. Juko-Pecirep, and U. B. Gyllensten, "Interaction of immunological genes on chromosome $2 \mathrm{q} 33$ and IFNG in susceptibility to cervical cancer," Gynecologic Oncology, vol. 116, no. 3, pp. 544-548, 2010.

[37] V. A. Govan, H. R. O. Carrara, J. A. Sachs, M. Hoffman, G. A. Stanczuk, and A.-L. Williamson, "Ethnic differences in allelic distribution of IFN-g in South African women but no link with cervical cancer," Journal of Carcinogenesis, vol. 2, article 3, 2003.

[38] A. P. M. Fernandes, M. A. G. Gonçalves, R. T. Simões, C. T. Mendes-Junior, G. Duarte, and E. A. Donadi, "A pilot 
case-control association study of cytokine polymorphisms in Brazilian women presenting with HPV-related cervical lesions," European Journal of Obstetrics Gynecology and Reproductive Biology, vol. 140, no. 2, pp. 241-244, 2008.

[39] Y.-Y. Mi, Q.-Q. Yu, B. Xu et al., "Interferon gamma +874 T/A polymorphism contributes to cancer susceptibility: a metaanalysis based on 17 case-control studies," Molecular Biology Reports, vol. 38, no. 7, pp. 4461-4467, 2011.

[40] C. M. Hawrylowicz and A. O'Garra, "Potential role of interleukin-10-secreting regulatory $\mathrm{T}$ cells in allergy and asthma," Nature Reviews Immunology, vol. 5, no. 4, pp. 271-283, 2005.

[41] E. Alamartine, P. Berthoux, C. Mariat, F. Cambazard, and F. Berthoux, "Interleukin-10 promoter polymorphisms and susceptibility to skin squamous cell carcinoma after renal transplantation," Journal of Investigative Dermatology, vol. 120, no. 1, pp. 99-103, 2003.

[42] G. A. Stanczuk, E. N. Sibanda, C. Perrey et al., "Cancer of the uterine cervix may be significantly associated with a gene polymorphism coding for increased IL-10 production," International Journal of Cancer, vol. 94, no. 6, pp. 792-794, 2001.

[43] M. Zoodsma, I. M. Nolte, M. Schipper et al., "Interleukin-10 and Fas polymorphisms and susceptibility for (pre)neoplastic cervical disease," International Journal of Gynecological Cancer, vol. 15, no. 6, pp. 282-290, 2005.

[44] K. Szöke, A. Szalmás, G. Szládek et al., "IL-10 promoter nt 1082A/G polymorphism and human papillomavirus infection in cytologic abnormalities of the uterine cervix," Journal of Interferon and Cytokine Research, vol. 24, no. 4, pp. 245-251, 2004.

[45] G. Barbisan, L. O. Pérez, A. Contreras, and C. D. Golijow, "TNF- $\alpha$ and IL-10 promoter polymorphisms, HPV infection, and cervical cancer risk," Tumor Biology, vol. 33, no. 5, pp. 15491556, 2012. 

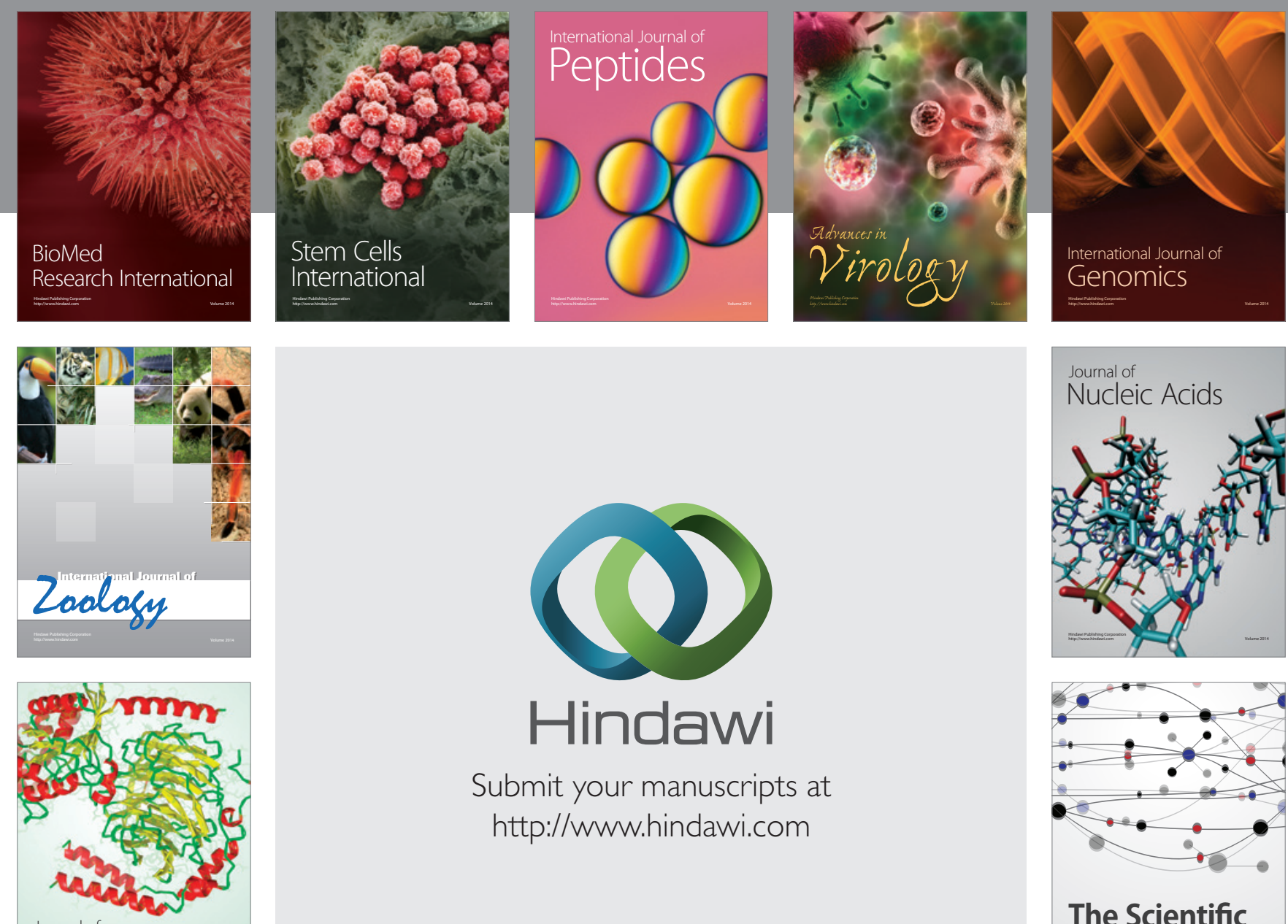

Submit your manuscripts at

http://www.hindawi.com

Journal of
Signal Transduction
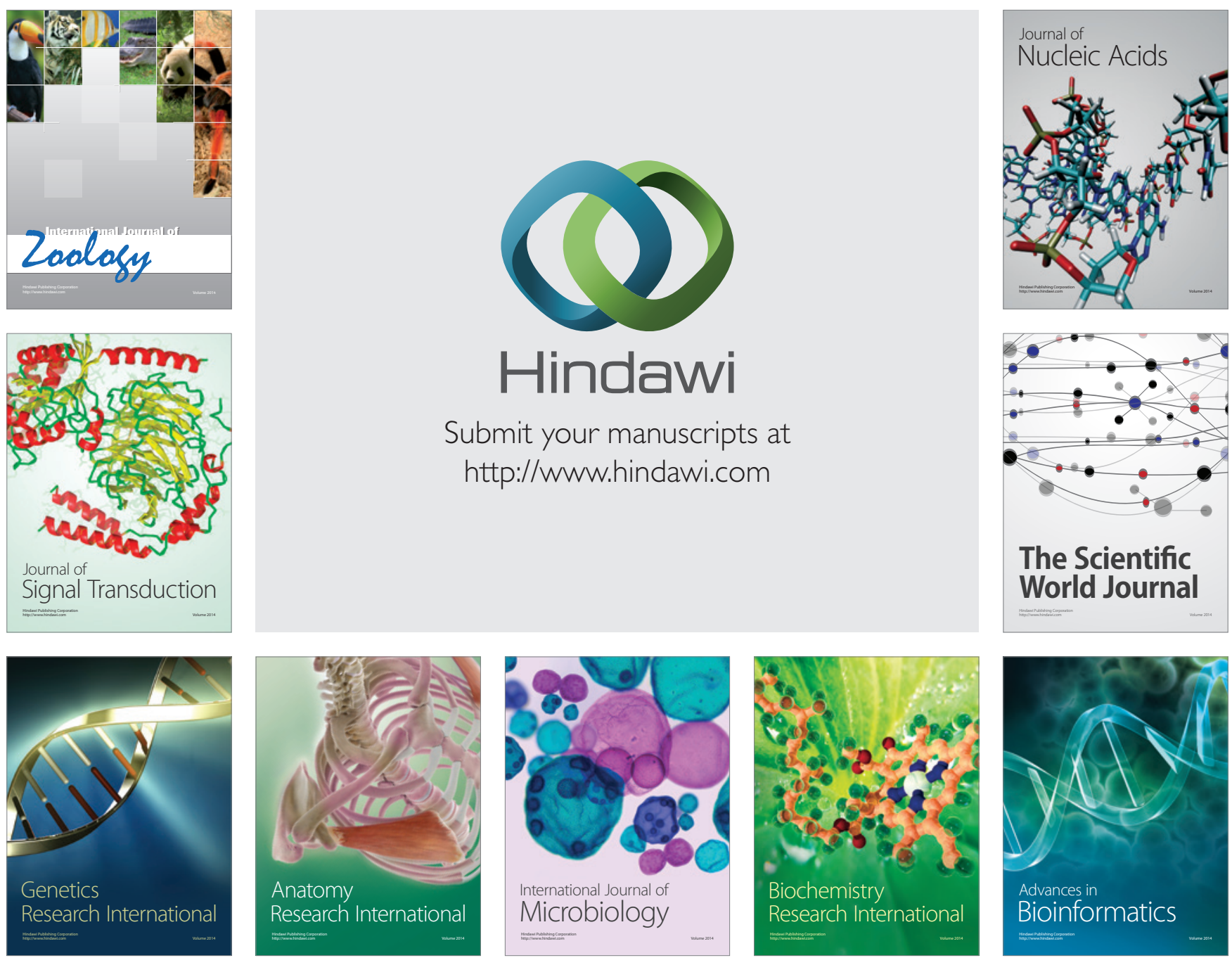

The Scientific World Journal
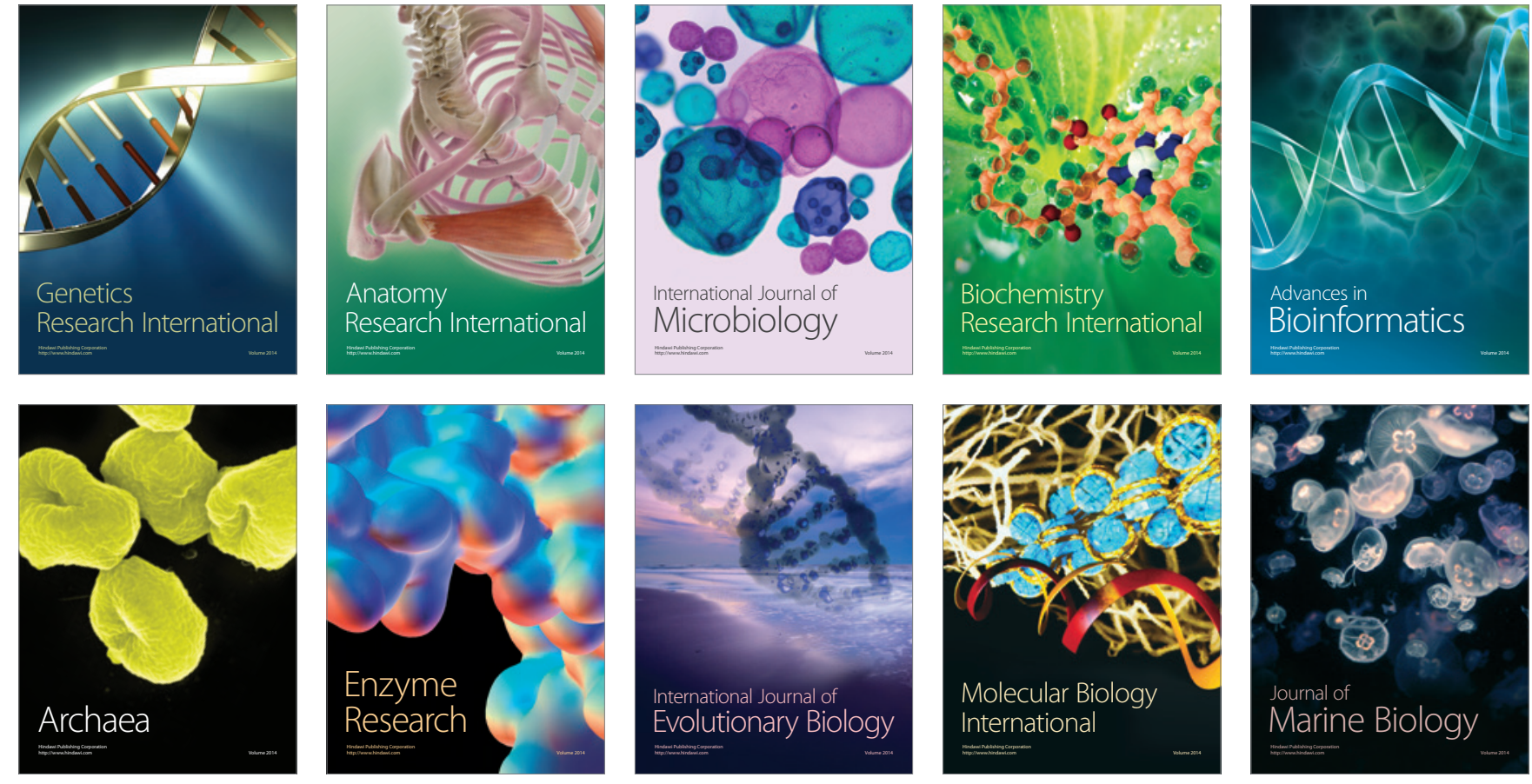